\title{
Determination of Oxygen Solubility in Liquid Media
}

\author{
Francielo Vendruscolo, ${ }^{1}$ Márcio José Rossi, ${ }^{2}$ Willibaldo Schmidell, ${ }^{1}$ and Jorge Luiz Ninow ${ }^{1}$ \\ ${ }^{1}$ Chemical and Food Engineering Department, Federal University of Santa Catarina (UFSC), P.O. Box 476, \\ 88040-900 Florianópolis, SC, Brazil \\ ${ }^{2}$ Microbiology, Immunology and Parasitology Department, Federal University of Santa Catarina (UFSC), P.O. Box 476, \\ 88040-900 Florianópolis, SC, Brazil
}

Correspondence should be addressed to Francielo Vendruscolo, francielo@hotmail.com

Received 23 February 2012; Accepted 26 April 2012

Academic Editors: G. Bayramoglu and A. Brucato

Copyright (c) 2012 Francielo Vendruscolo et al. This is an open access article distributed under the Creative Commons Attribution License, which permits unrestricted use, distribution, and reproduction in any medium, provided the original work is properly cited.

\begin{abstract}
The present work aimed at determining the oxygen saturation in culture medium used in the production of pigments by Monascus ruber CCT 3802. This estimation allows the correction and the minimization of errors on the specific oxygen uptake rates determination because the conversion of oxygen partial pressure to oxygen concentration requires accurate information on oxygen solubility in experimental incubation media. By adding hydrogen peroxide and then transforming into water and oxygen using catalase, it was possible to determinate the saturation concentration of 7.677 and $6.772 \mathrm{mgO}_{2} \mathrm{~L}^{-1}$ in distilled water and in growth medium, respectively. The determination of these parameters makes possible the minimization of errors on the specific oxygen uptake rates determination, once many studies consider the saturation concentration in distilled water.
\end{abstract}

\section{Introduction}

The main purpose of a stirring system is the oxygen supply to keep the cell respiratory activity. Thus, the point is to transfer the oxygen from the gas phase to the liquid phase and let the dissolved oxygen reach the suspended cells, penetrating into the cells and, finally, being consumed in the reaction [1]. The mechanism of oxygen transfer from the gas phase to the liquid phase is controlled by the liquid phase mass transfer resistance. The rate of mass transfer or the rate of oxygen absorption can be stated mathematically. Therefore, for studying both the oxygen transfer and the uptake kinetics of the cells, it is essential to know about the values of saturation oxygen concentration in the liquid phase and concentration of oxygen in the liquid phase [2].

One of the greatest difficulties faced when oxygen transfer and oxygen consumption are used is the determination of Henry's law constant $H$, which will be used as reference to calculate the saturation concentration and the specific oxygen uptake rates. The $\mathrm{O}_{2}$ concentration in the liquid can be determined by Winkler's method [3], which consists in determining the liquid chlorosity. Galvanic and polarographic electrodes measure the partial pressure of dissolved oxygen or oxygen tension in the fermentation broth, not the dissolved oxygen concentration. Thus, data are in terms of relative fraction saturation. To convert this to dissolved oxygen concentration, it is necessary to know the solubility of oxygen in the liquid at the temperature and pressure of measurement.

Oxygen has a low solubility in aqueous medium. Its solubility in distilled water is only about $7 \mathrm{mg} \mathrm{L}^{-1}$ at $30^{\circ} \mathrm{C}$. This amount of oxygen is quickly consumed in aerobic cultures and must be constantly replaced by air sparging. In batch culture, rate of oxygen uptake varies with time, the concentration of cells increases during the course of batch culture, and the total rate of oxygen uptake is proportional to the number of cells present. In addition, the rate of oxygen consumption per cell, known as the specific oxygen uptake rate, also varies. However, when the level of dissolved oxygen in the medium falls below a certain point, the specific rate of oxygen uptake is also dependent on the oxygen concentration in the liquid [4].

In the bioprocess industry, synthetic and/or complex culture media are used. Gas solubility data are required to establish mass balance, calculate yields coefficients, volumetric mass transfer coefficients by gas balance techniques, and 
design and scale up bioreactors in gas-limiting conditions. Because oxygen partial pressure in the gas phase and presence of dissolved material in the liquid are major factors affecting oxygen solubility, the values of oxygen solubility in water cannot be applied directly to bioprocess systems.

It is known that, during the microbial culture at a given culture medium, there is a general stoichiometry in the process. There is the nutrient consumption, with subsequently formation of biomass, final and intermediate products from cell metabolism [5] and increased to viscosity of growth media [6]. Various authors have demonstrated the leading importance of the substrate oxygen. According to Gupta and Rao [7], Pérez et al. [8], and Garcia-Ochoa and Gomez [9], changes in oxygen availability may lead to drastic effects on fermentation kinetics and reactor performance. Clark et al. [10] demonstrated that oxygen limitation acts in an analogous manner to substrate limitation, and Katzer et al. [11] verified that the production of secondary metabolites not only is influenced by factors like nitrogen or phosphate limitation but may also be dependent on oxygen limitation.

The scarcity of experimental data and the complexity of microbial culture media have prompted the development of several methods of estimation and prediction of solubility in such solutions [12]. In a typical fermentation medium, oxygen solubility is between 5 and $25 \%$ lower than in water as a result of solute effects $[1,4,5]$. Precise knowledge of the solubility of oxygen is very important in cultures that require control of the critical oxygen concentration in the culture medium or to prevent oxidative stress, which can be extremely damaging to sensitive cultures such as mammalian cells [13].

Conversion of oxygen partial pressure to oxygen concentration requires accurate information on oxygen solubility in experimental incubation media [14]. Due to the difficulty of measurement, the availability of experimental data is limited and cannot satisfy the engineering demand. The aim of this work was to determine oxygen solubility in culture medium used to produce natural pigments by Monascus ruber CCT 3802 .

\section{Material and Methods}

2.1. Microorganism and Culture Medium. Monascus ruber CCT 3802 was obtained from the Tropical Culture Collection André Tosello (Campinas, SP, Brazil). The strain was frozen at $-20^{\circ} \mathrm{C}$ after adding $100 \mu \mathrm{L}$ glycerol $\mathrm{mL}^{-1}$ spore suspension as a cryoprotectant. The culture was maintained on potato dextrose agar (PDA) in tubes and Roux bottles previously sterilized at $121^{\circ} \mathrm{C}$ for $15 \mathrm{~min}$, incubated at $30^{\circ} \mathrm{C}$ for 7 days, and subsequently stored at $4^{\circ} \mathrm{C}$. The inoculum and culture medium were prepared according to Vendruscolo et al. [6] containing, per liter $20 \mathrm{~g}$ glucose, $5 \mathrm{~g}$ glycine, $2.5 \mathrm{~g} \mathrm{KH}_{2} \mathrm{PO}_{4}$, $2.5 \mathrm{~g} \mathrm{~K}_{2} \mathrm{HPO}_{4}, 0.5 \mathrm{~g} \mathrm{MgSO}_{4} \cdot 7 \mathrm{H}_{2} \mathrm{O}, 0.1 \mathrm{~g} \mathrm{FeSO}_{4} \cdot 7 \mathrm{H}_{2} \mathrm{O}, 0.1 \mathrm{~g}$ $\mathrm{CaCl}_{2}, 0.03 \mathrm{~g} \mathrm{MnSO} 4$, and $0.01 \mathrm{~g} \mathrm{ZnSO}_{4}$. After sterilization the initial $\mathrm{pH}$ was adjusted with $1 \mathrm{M} \mathrm{NaOH}$ or $\mathrm{HCl}$ to 4.0.

2.2. Inoculum Preparation. Monascus ruber CCT 3802 was initially grown on PDA medium in a Roux bottle incubated at $30^{\circ} \mathrm{C}$ for 7 days and subsequently stored at $4^{\circ} \mathrm{C}[6,15]$. A spore suspension was obtained by washing the Roux bottle cultures with a sterile aqueous solution of $0.1 \%$ Tween 80 . Fungal mycelia were obtained by germination of the spores suspended in a $1,000 \mathrm{~mL}$ baffled flask containing $400 \mathrm{~mL}$ of inoculum culture medium at $30^{\circ} \mathrm{C}$ and shaken on a rotary shaker at $120 \mathrm{rpm}$ for 60 hours. This suspension was used for further inoculation in a bioreactor.

2.3. Stirred Tank Fermentation. Fermentation was carried out in a $6 \mathrm{~L}$ (working volume of $4 \mathrm{~L}$ ) batch bioreactor (Bioflo III from New Brunswick Scientific Co., New Jersey, USA) for 84 hours. The bioreactor has a vessel with an internal diameter of $0.170 \mathrm{~m}$, a rounded bottom, and a height/diameter ratio of 1.4. Agitation was provided by two six-blade Rushton turbines with a $d / t$ ratio of 0.38 and a $w / d$ ratio of 0.18 . The culture medium $(3.6 \mathrm{~L})$ was inoculated with $0.4 \mathrm{~L}$ of the inoculum culture $\left(10 \% \mathrm{v} / \mathrm{v} ; \approx 0.5 \mathrm{~g} \mathrm{~L}^{-1}\right.$ dry equivalent of cells), under the following conditions: temperature $30^{\circ} \mathrm{C}$, stirring speed of $300 \mathrm{rpm}$, and specific aeration rate of $0.6 \mathrm{vvm}$ (volume of air per volume of batch per minute) [6]. During cultivation, $500 \mathrm{~mL}$ of sample was taken at times $0,24,48$, and 72 hours, followed by filtration through Whatman no. 1 filter paper (Madiston, UK). The biomass was discarded and the filtrate was submitted to the oxygen solubility, glucose, biomass, and red pigment determinations. Saturation concentration of initial time was determined before inoculation of microorganism.

2.4. Glucose, Biomass, and Pigment Determination. Residual glucose concentration in the culture medium was estimated by the 3,5-dinitrosalicylic acid (DNS) method [16]. The biomass was determined gravimetrically by dry weight by filtration of $10 \mathrm{~mL}$ of a growth medium samples through a Whatman filter paper no. 1 (Madiston, UK). The filtrate was submitted to red pigment determination by spectrophotometer Spectronic Unicam Genesys 10vis (New York, USA) at $480 \mathrm{~nm}$ : 1 unit optic density (OD) at $480 \mathrm{~nm}$ corresponding to $15 \mathrm{mg}$ of red pigment by liter of growth media [17].

2.5. Oxygen Solubility Determination. The equation that describes the solubility of a gas in a liquid, to diluted solutions, is Henry's law:

$$
C_{S}=H \cdot p_{\mathrm{O}_{2}},
$$

where $C_{S}$ is the saturation $\mathrm{O}_{2}$ concentration in the liquid $\left(\mathrm{mgO}_{2} \mathrm{~L}^{-1}\right), \mathrm{H}$ is Henry's law constant $\left(\mathrm{mgO}_{2} \mathrm{~L}^{-1} \mathrm{~atm}^{-1}\right)$, and $p_{\mathrm{O}_{2}}$ is the oxygen partial pressure in the gas (atm). The oxygen solubility determinations in samples (distilled water and the culture medium filtrate at $0,24,48$, and 72 hours of growth) were performed using the proposed method by Käppeli and Fiechter [2], adapted to laboratory conditions.

The method consists in the addition of a known quantity of oxygen by the decomposition of hydrogen peroxide $\left(\mathrm{H}_{2} \mathrm{O}_{2}\right)$ via catalase action, producing oxygen and water and the measurement of the correspondent saturation percentage, as described by reaction stoichiometry shown in

$$
\mathrm{H}_{2} \mathrm{O}_{2}+\text { catalase } \longrightarrow \frac{1}{2} \mathrm{O}_{2}+\mathrm{H}_{2} \mathrm{O}
$$




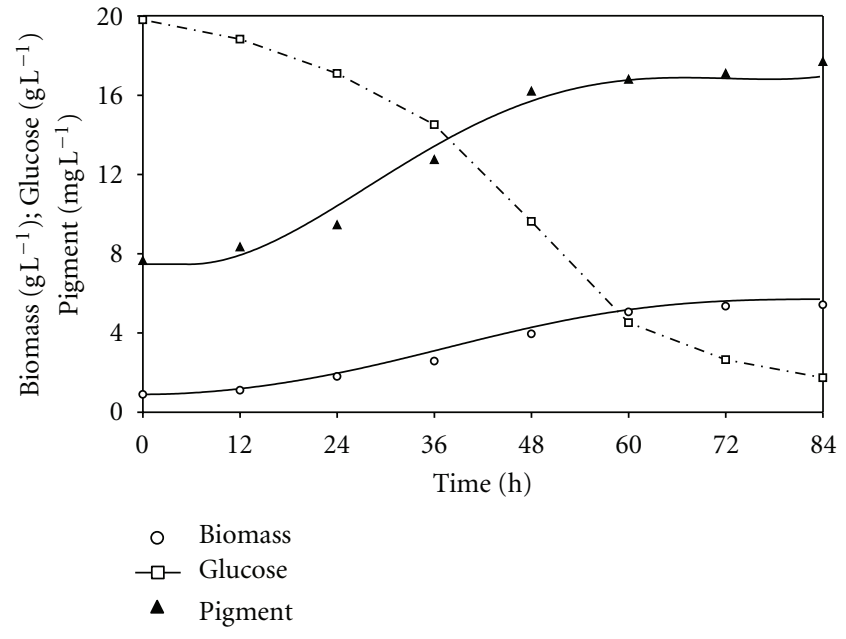

Figure 1: Monascus ruber CCT 3802 cultivations in a stirred tank bioreactor (temperature $30^{\circ} \mathrm{C}$, stirring speed $300 \mathrm{rpm}$, specific aeration rate $0.6 \mathrm{vvm}$, and initial $\mathrm{pH} 5.0$ ).

The experiments were performed in a $500 \mathrm{~mL}$, threenecked, round-bottomed flask. One of the openings was used to insert the oxygen probe InPro 6800 Mettler Toledo (detection limit of $4 \mathrm{ppb}$ ), previously polarized during $360 \mathrm{~min}$ and calibrated with saturated water at $30^{\circ} \mathrm{C}$. Another opening was used to allow the addition of $\mathrm{N}_{2}$ (inert gas) over the surface (to prevent oxygen transfer from the headspace) and eliminate $\mathrm{O}_{2}$ remained concentration in the samples. The third neck served for the addition of reactants, $360 \mathrm{~mL}$ of samples, hydrogen peroxide $\left(\mathrm{H}_{2} \mathrm{O}_{2}\right.$ was standardized using potassium permanganate) and catalase enzyme TERMINOX ULTRA $50 \mathrm{~L}$ supplied by NOVOZYMES. The reaction vessel was placed in a thermostat water bath at $30^{\circ} \mathrm{C}$ and equipped with a magnetic stirrer.

The oxygen removal of samples was performed by bubbling $\mathrm{N}_{2}$. When the oxygen probe value was equal or lower than $1 \%, \mathrm{H}_{2} \mathrm{O}_{2}$ was added to the culture medium filtrate and then catalase was added in excess ( $x$ microliters). The saturation percentage reading by oxygen probe was made when the value was holding constant. The procedure was performed for different volumes of $\mathrm{H}_{2} \mathrm{O}_{2}$, obtaining different percentages of oxygen saturation in the liquids. The slopes of oxygen saturation percentage versus those of the amounts of oxygen added to the medium (2) were possible to estimate the oxygen saturation concentration for $100 \%$ saturation and Henry's law constant using (1).

\section{Results and Discussion}

A typical batch-mode fermentation time course of Monascus ruber CCT 3802, in a medium containing $5 \mathrm{~g} \mathrm{~L}^{-1}$ glycine and $20 \mathrm{~g} \mathrm{~L}^{-1}$ glucose, with a stirrer speed of $300 \mathrm{rpm}$ and an aeration rate of $0.3 \mathrm{vvm}$ conducted to estimate the oxygen solubility in culture medium, is shown in Figure 1.

In the filamentous fungus it appears that from 48 hours of cultivation the biomass production is greatly reduced,

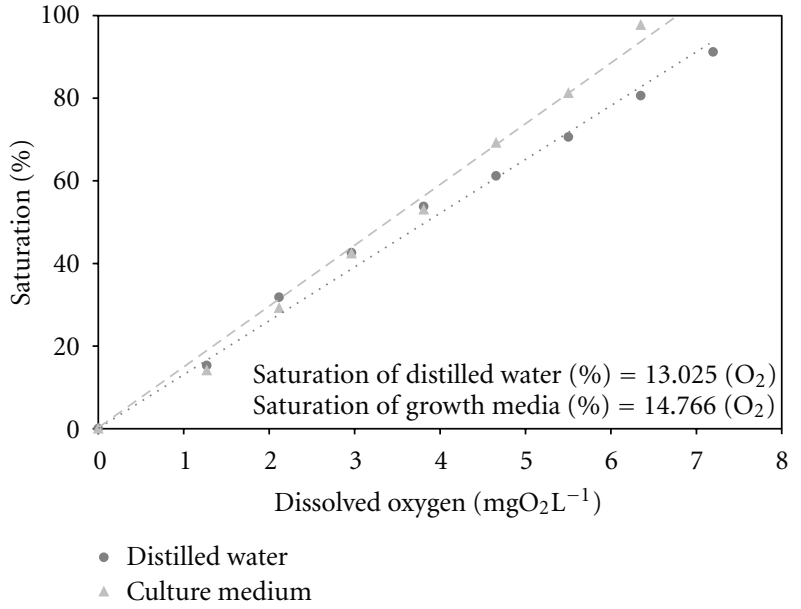

Figure 2: Probe response of dissolved oxygen at $30^{\circ} \mathrm{C}$ to increased $\mathrm{H}_{2} \mathrm{O}_{2}$ volumes in distilled water and in culture medium at initial time.

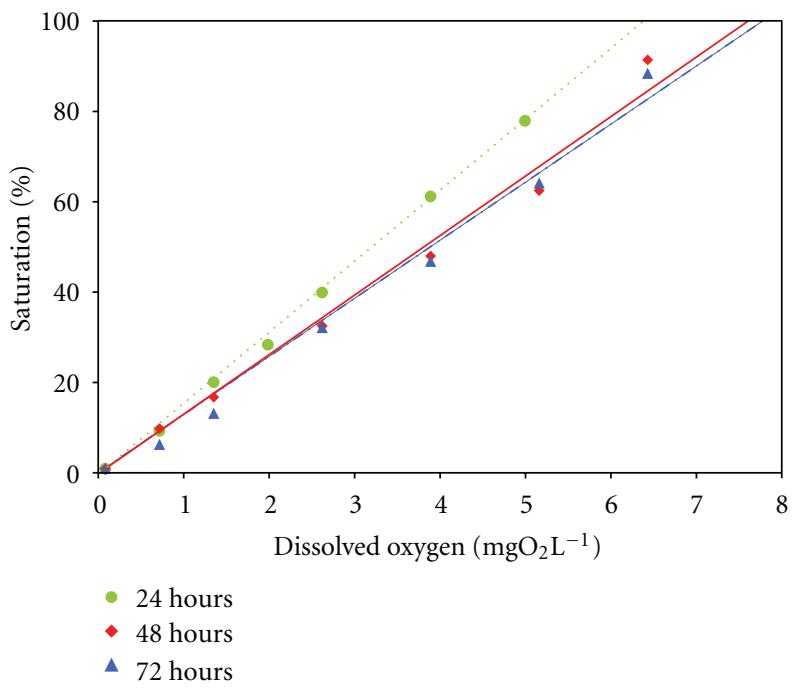

Figure 3: Probe response of dissolved oxygen at $30^{\circ} \mathrm{C}$ to increased $\mathrm{H}_{2} \mathrm{O}_{2}$ volumes in culture medium at different times of cultivation.

reaching the stationary phase of growth, while glucose consumption continues to occur. The red pigment was produced throughout the fermentation and reached a concentration of $17.7 \mathrm{mg} \mathrm{L}^{-1}$. The pigment production is done in a manner associated with growth, and pigment production ceases as of 60 hours, indicating that from this time many are already in nutrient depletion, reducing the growth of microorganisms, except for glucose that remains at approximately $4.1 \mathrm{~g} \mathrm{~L}^{-1}$, being gradually consumed by the end of cultivation.

The oxygen solubility at $30^{\circ} \mathrm{C}$ in distilled water and in the culture medium is shown in Figures 2 and 3. By using Henry's law (1), it was possible to determinate the values of the $H$ constant in each experiment. The results for the oxygen solubility in the culture medium, measured at different culture times and in distilled water, as well as the Henry's law constant, correlation index, and relative 
TABLE 1: Oxygen solubility in distilled water and the culture medium during Monascus ruber CCT 3802 cultivation.

\begin{tabular}{|c|c|c|c|c|c|}
\hline \multirow{2}{*}{ Response* } & \multirow{2}{*}{ Distilled water } & \multicolumn{4}{|c|}{ Culture medium } \\
\hline & & $0 \mathrm{~h}^{* *}$ & $24 \mathrm{~h}$ & $48 \mathrm{~h}$ & $72 \mathrm{~h}$ \\
\hline$C_{S}\left(\mathrm{mgO}_{2} \mathrm{~L}^{-1}\right)$ & 7.677 & 6.772 & 6.393 & 7.580 & 7.743 \\
\hline$H\left(\mathrm{mgO}_{2} \mathrm{~L}^{-1} \mathrm{~atm}^{-1}\right)$ & 36.559 & 32.324 & 30.515 & 36.181 & 36.959 \\
\hline$R^{2}$ & 0.993 & 0.996 & 0.999 & 0.996 & 0.992 \\
\hline Relative Deviation $(\%)^{* * *}$ & & -11.78 & -16.72 & -1.27 & +0.86 \\
\hline
\end{tabular}

${ }^{*}$ Obtained at $30^{\circ} \mathrm{C} .{ }^{* *}$ Determination performed in the culture medium before inoculation of microorganism. ${ }^{* *}$ Variation concerning the distilled water experiment $\left(\mathrm{pO}_{2}=0.20946 \mathrm{~atm}\right)$.

deviation when compared to the experiments in distilled water are shown in Table 1 . The saturation $\mathrm{O}_{2}$ concentration in the liquid medium is proportional to the partial pressure of the oxygen in the gas phase, and this proportionality is given by Henry's constant $(H)$. Since the $H$ is function of the nutrient concentration, this explains variation of $H$ observed.

The results presented in Table 1 show that the oxygen solubility in the culture medium before inoculation of microorganism was $6.772 \mathrm{mgO}_{2} \mathrm{~L}^{-1}, 11.8 \%$ lower when compared to the oxygen solubility in distilled water $\left(7.677 \mathrm{mgO}_{2} \mathrm{~L}^{-1}\right)$. Saturation percentageversus dissolved oxygen data was highly linear as shown in Figures 2 and $3\left(R^{2}>0.99\right)$. At the other hand, the oxygen solubility in the culture medium after 48 and 72 hours was the same found in the experiment with distilled water, 7.580 and $7.743 \mathrm{mg} \mathrm{L}^{-1}$, respectively. It can be explained due to the nutrient consumption in the medium by the microorganism. As a result, it can be verified that the products do not affect the oxygen solubility with the same magnitude when compared to the initial nutrients found in the culture medium. Our analysis indicates that changes in sugar concentration are primarily responsible for changes in oxygen solubility during the course of glucose consumption.

A relative deviation of 11.8 and $16.7 \%$ indicates errors during the specific oxygen uptake rates calculations by considering the saturation $\mathrm{O}_{2}$ concentration in distilled water instead of the real saturation concentration in the culture medium. Schmidell [1] reports that, in many cases, when the dissolved oxygen concentration is not corrected, there can be errors at the range of 10 to $15 \%$. Rossi [18] reported a variation of $8 \%$ in the oxygen saturation concentration in distilled water when compared to culture medium used for ectomycorrhizal fungi production. Henzler and Kauling [19] verified a reduction of $9 \%$ in oxygen solubility in the culture medium when compared to distilled water. Kothandaraman [20] reviewed the effects of detergent contaminants on oxygen solubility measurements, and for several natural waters he found as much as $8 \%$ difference from distilled water because of contaminants. Slininger et al. [21] determined the oxygen solubility using a colorimetric method during glucose and xylose fermentations and observed that xylose and glucose at $230 \mathrm{~g} \mathrm{~L}^{-1}$ lowered oxygen solubility to $71 \%$ of that for the sugar-free medium. Xylitol at $40 \mathrm{~g} \mathrm{~L}^{-1}$ lowered oxygen solubility of the media by $9 \%$. This is similar to the effect of $40 \mathrm{~g} \mathrm{~L}^{-1}$ xylose on oxygen solubility. However, xylose fermentations with potential for application produce less than $10 \mathrm{~g} \mathrm{~L}^{-1}$ xylitol, giving it only a minor role in determining oxygen solubility. Popovic et al. [22] arrived at similar results. Their solubility measurements on glucose and yeast extract solution differed from ours by less than $5 \%$.

These results show the importance of the determination of the oxygen solubility when oxygen transfer and oxygen consumption are required and also enriches the literature, since this determination hasnot been commonly performed in the consulted literature.

\section{Conclusion}

The analyzing method was successfully applied for measuring of oxygen solubility in liquid media and distilled water. The oxygen solubility in the culture medium was $11.8 \%$ lower than the saturation $\mathrm{O}_{2}$ concentration when compared to the saturation concentration in distilled water. When this variation is known, it becomes possible to increase the accuracy in the oxygen consumption analysis in a certain bioprocess. The correction of the solubility of oxygen in the culture medium increases the accuracy and precision in determining the specific oxygen uptake rates.

\section{Acknowledgments}

The authors wish to thank the NOVOZYMES for the Catalase TERMINOX ULTRA 50L supply, Conselho Nacional de Desenvolvimento Científico e Tecnológico ( $\mathrm{CNPq}-\mathrm{The}$ National Council for Scientific and Technological Development) for financial support (process no. 476056/2006-3) and the Coordenação de Aperfeiçoamento de Pessoal de Nivel Superior (CAPES-Committee for Professional Development of Higher Education Staff) for a research scholarship.

\section{References}

[1] W. Schmidell, "Transferência de oxigênio em biorreatores," in Biotecnologia Industrial, W. Schmidell, W. Borzani, U. A. Lima, and E. Aquarone, Eds., vol. 2, pp. 380-410, Edgard Blücher, São Paulo, Brazil, 2001.

[2] O. Käppeli and A. Fiechter, "A convenient method for the determination of oxygen solubility in different solutions," Biotechnology and Bioengineering, vol. 23, pp. 1897-1901, 1981.

[3] L. W. Winkler, "Die Bestimmung des im Wasser gelösten Sauerstoffes," Berichte der Deutschen Chemischen Gesellschaft, vol. 21, pp. 2843-2855, 1888.

[4] P. Doran, Bioprocess Engineering Principles, Elsevier Science \& Technology Books, Australia, 1995. 
[5] H. W. Blanch and D. S. Clark, Biochemical Engineering, New York, NY, USA, 1997.

[6] F. Vendruscolo, L. O. Pitol, B. A. M. Carciofi et al., "Construction and application a vane system in a rotational rheometer for determination of the rheological properties of Monascus ruber CCT 3802," Journal of Biorheology, pp. 1-7, 2010.

[7] A. Gupta and G. Rao, "A study of oxygen transfer in shake flasks using a non-invasive oxygen sensor," Biotechnology and Bioengineering, vol. 84, no. 3, pp. 351-358, 2003.

[8] J. Pérez, J. L. Montesinos, and F. Gòdia, "Gas-liquid mass transfer in an up-flow cocurrent packed-bed biofilm reactor," Biochemical Engineering Journal, vol. 31, no. 3, pp. 188-196, 2006.

[9] F. Garcia-Ochoa and E. Gomez, "Bioreactor scale-up and oxygen transfer rate in microbial processes: an overview," Biotechnology Advances, vol. 27, no. 2, pp. 153-176, 2009.

[10] G. J. Clark, D. Langley, and M. E. Bushell, "Oxygen limitation can induce microbial secondary metabolite formation: investigations with miniature electrodes in shaker and bioreactor culture," Microbiology, vol. 141, no. 3, pp. 663-669, 1995.

[11] W. Katzer, M. Blackburn, K. Charman, S. Martin, J. Penn, and S. Wrigley, "Scale-up of filamentous organisms from tubes and shake-flasks into stirred vessels," Biochemical Engineering Journal, vol. 7, no. 2, pp. 127-134, 2001.

[12] J. B. Gros, C. G. Dussap, and M. Catté, "Estimation of $\mathrm{O}_{2}$ and $\mathrm{CO}_{2}$ solubility in microbial culture media," Biotechnology Progress, vol. 15, no. 5, pp. 923-927, 1999.

[13] Y. Shi, D. D. Y. Ryu, and S. H. Park, "Performance of mammalian cell culture bioreactor with a new impeller design," Biotechnology and Bioengineering, vol. 40, no. 2, pp. 260-270, 1992.

[14] E. Gnaiger, "Oxygen calibration and solubility in experimental media," Mitochondrial Physiology Network, vol. 6, pp. 1-12, 2010.

[15] R. M. Meinicke, F. Vendruscolo, D. E. Moritz et al., "Potential use of glycerol as substrate for the production of red pigments by Monascus ruber in submerged fermentation," Biocatalysis and Agricultural Biotechnology, vol. 1, pp. 238-242, 2012.

[16] G. L. Miller, "Use of dinitrosalicylic acid reagent for determination of reducing sugar," Analytical Chemistry, vol. 31, no. 3, pp. 426-428, 1959.

[17] H. Hajjaj, A. Klaébé, M. O. Loret, T. Tzédakis, G. Goma, and P. J. Blanc, "Production and identification of N-glucosylrubropunctamine and N-glucosylmonascorubramine from Monascus ruber and occurrence of electron donor-acceptor complexes in these red pigments," Applied and Environmental Microbiology, vol. 63, no. 7, pp. 2671-2678, 1997.

[18] M. J. Rossi, Tecnologia para produção de inoculantes de fungos ectomicorrízicos utilizando cultivo submerso em biorreator airlift [Tese de Doutorado], Universidade Federal de Santa Catarina, Florianópolis, Brazil, 2006.

[19] H. J. Henzler and D. J. Kauling, "Oxygenation of cell cultures," Bioprocess Engineering, vol. 9, no. 2-3, pp. 61-75, 1993.

[20] Kothandaraman, "Effects of contaminants on reaeration rates in river water," Journal of the Water Pollution Control Federation, vol. 43, no. 5, pp. 806-817, 1971.

[21] P. J. Slininger, R. J. Petroski, J. Bothast, M. R. Ladisch, and M. R. Okos, "Measurement of oxygen solubility in fermentation media: a colorimetric method," Biotechnology and Bioengineering, vol. 33, pp. 578-583, 1989.

[22] M. Popovic, H. Niebelschiitz, and M. Reub, "Oxygen solubilities in fermentation fluids," European Journal of Applied Microbiology and Biotechnology, vol. 8, no. 1, 1979. 

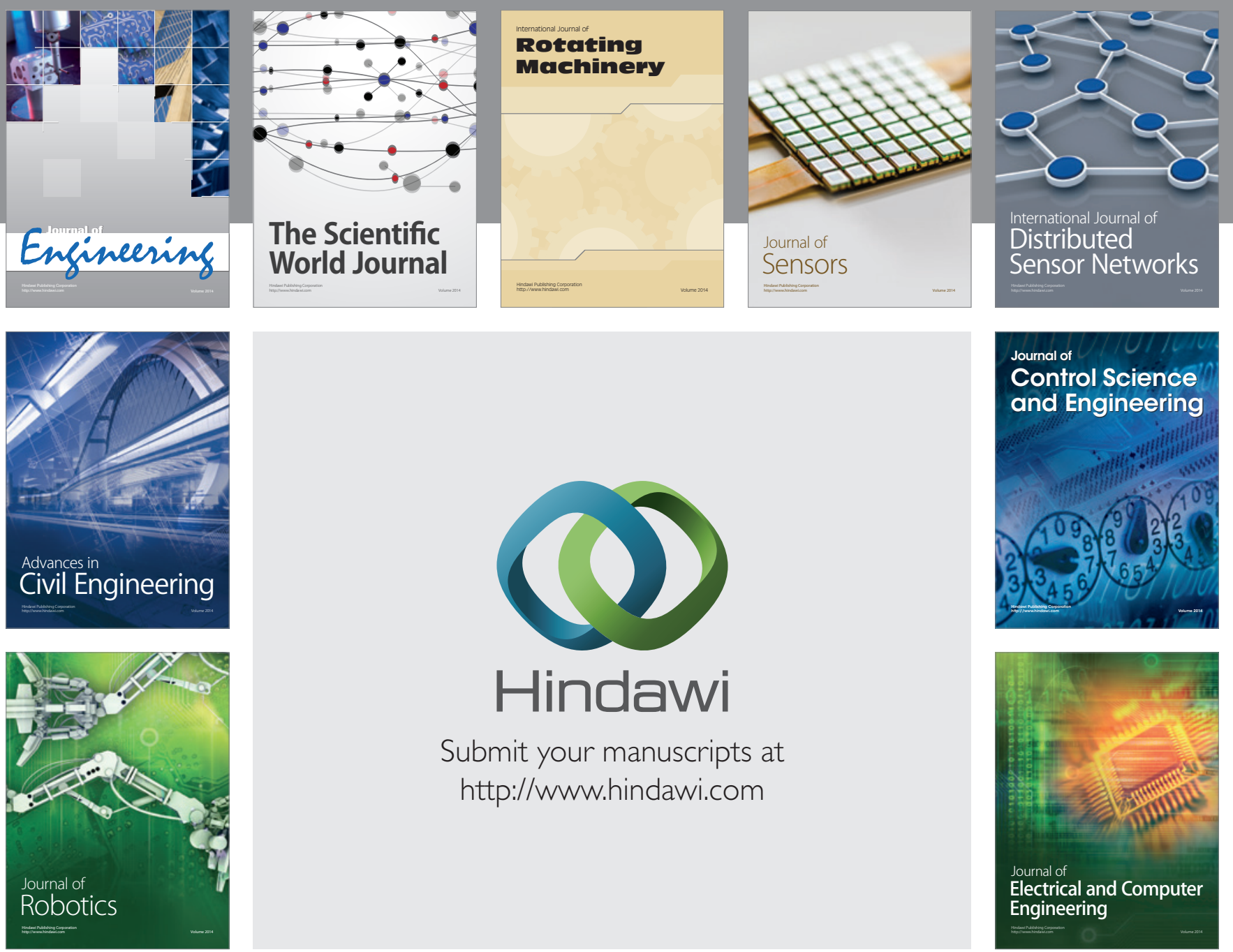

Submit your manuscripts at

http://www.hindawi.com
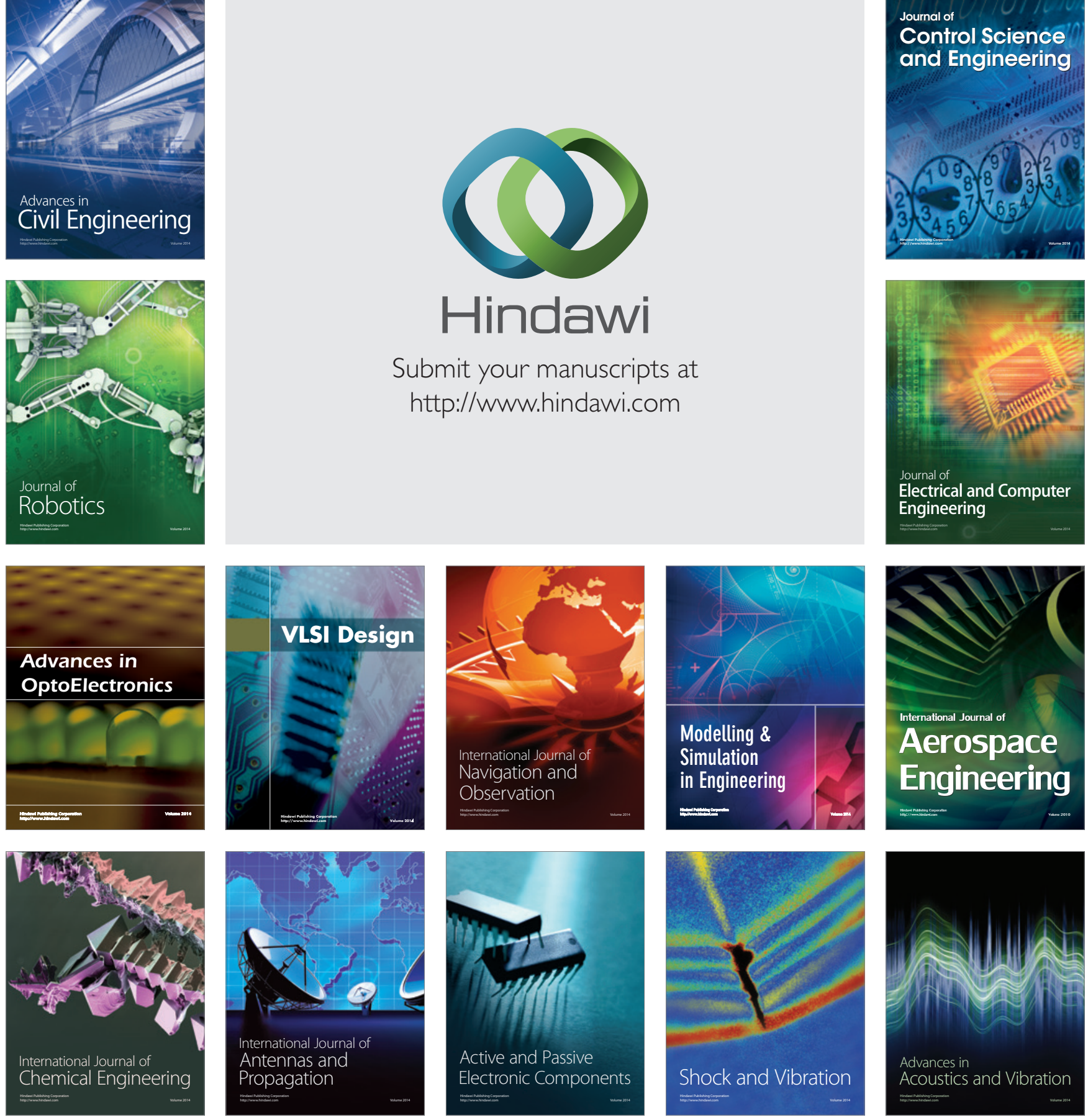